DOI: https://doi.org/10.34069/AI/2020.35.11.3

\title{
Grammatical and Syntactical Functions of Auxiliaries in English and Urdu
}

\author{
Funciones gramaticales y sintácticas de los auxiliares en inglés y urdu
}

Received: October 1, 2020

Accepted: November 31, 2020

\author{
Written by: \\ Asif Aziz \\ Tahir Saleem ${ }^{8}$ \\ Binish Maqsood ${ }^{9}$ \\ Zanib Ameen ${ }^{10}$
}

\begin{abstract}
The current study investigates grammatical and syntactical functions of auxiliaries in Urdu and English to draw certain distinctions regarding the behavior, syntactic representation and semantic content auxiliaries add to the main verbs (Vs) through the X-bar theory as a theoretical framework within the minimalist program (MP). The data of the current research were collected from authentic sources (Urdu and English text books and grammars) to consider a diverse range of possible usage of Urdu and English auxiliaries. 200 sentences extracted from textbooks and grammars were analyzed grammatically in terms of morphology, and syntax (through treerepresentation and their movement). The findings indicate sharp differences related to the syntactic position of auxiliaries in Urdu and English. In Urdu, auxiliaries always occupy their position after the main verbs in a sentence and their position is fixed and also have the ability to mark number (singular \& plural) and gender (masculine \& feminine). In contrast, English auxiliaries can only mark number. Another sharp difference is observed in the question formation process. In Urdu, unlike English, auxiliaries cannot be moved from its latent position towards the specifier position at the beginning of the sentence to construct question structures, because, if it happens, the sentence is considered ungrammatical which may result in the violation of MP. The findings of the study would prove helpful for understanding the semantic, grammatical and syntactical nature and behavior of auxiliaries comparatively in Urdu and English.
\end{abstract}

\section{Resumen}

El presente estudio investiga las funciones gramaticales y sintácticas de los auxiliares en urdu e inglés para establecer ciertas distinciones con respecto al comportamiento, la representación sintáctica y el contenido semántico que los auxiliares agregan a los verbos principales (Vs) a través de la teoría X-bar como marco teórico dentro del programa minimalista. (MP). Los datos de la investigación actual se obtuvieron de fuentes auténticas (libros de texto y gramáticas en urdu e inglés) para considerar una amplia gama de posibles usos de auxiliares en urdu e inglés. Se analizaron gramaticalmente 200 oraciones extraídas de libros de texto y gramáticas en términos de morfología y sintaxis (a través de la representación de árboles y su movimiento). Los hallazgos indican marcadas diferencias relacionadas con la posición sintáctica de los auxiliares en urdu e inglés. En urdu, los auxiliares siempre ocupan su posición después de los verbos principales en una oración y su posición es fija y también tienen la capacidad de marcar el número (singular y plural) y el género (masculino y femenino). Por el contrario, los auxiliares ingleses solo pueden marcar números. Se observa otra marcada diferencia en el proceso de formación de preguntas. En urdu, a diferencia del inglés, los auxiliares no se pueden mover de su posición latente a la posición del especificador al comienzo de la oración para construir estructuras de preguntas, porque, si sucede, la oración se considera agramatical, lo que puede resultar en la violación de MP. Los hallazgos del estudio ayudarían a comprender la naturaleza semántica,

\footnotetext{
${ }^{7}$ M.Phil in Applied Linguistics, Department of English, University of Lahore Pakistan.

${ }^{8} \mathrm{PhD}$ in Linguistics and Literature, Assist. Professor, Department of English, University of Central Punjab Lahore Pakistan.

${ }^{9}$ M.Phil in Applied Linguistics, Department of English, University of Lahore Pakistan.

${ }^{10}$ M.Phil in Applied Linguistics, Department of English, University of Lahore Pakistan.
} 


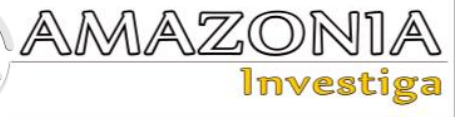

Keywords: Grammatical, syntactical, X-bar theory, minimalist program, auxiliaries, ungrammatical, syntactic nature.

\section{Introduction}

Auxiliaries refer back to the Latin language for their origin, and in modern English, mean to add something to the meaning of the verb (Vs) or to support; so an auxiliary verb is such a kind of verb that supports the main verb of the sentence. Alagbe (2009) claims English Auxiliaries are often referred to as supporting verbs due to their supportive nature which they exhibit during the communication. It is stated that auxiliaries (Yusupov et al., 2018) are an essential part of the verb group and only share the information related to grammar i.e., person, gender, aspect, tense, mood, and voice. Consider the following illustration in this respect:

[1] She has boiled the milk.

In this example, the auxiliary has aptly conveyed the information about the tense i.e. present perfect and third-person singular, whereas, the main verb in the example (1) tells us about the state of milk which is changed. There has been a lot of discussion regarding the difference between the main verbs and auxiliaries. Auxiliaries are treated as helping verb, light verbs, and support verbs. Collins and Hollo (2016) argue that verbs generally can be classified into main verbs and auxiliaries/light verbs on the basis of their functions. In the verb phrase, the main verb acts as the head of the VP while the auxiliary/light verb acts as their dependent. This type of distinction is common in gramatical y sintáctica y el comportamiento de los auxiliares comparativamente en urdu e inglés.

Palabras clave: gramatical, sintáctica, teoría Xbar, programa minimalista, auxiliares, agramatical, sintáctica.

all the languages that exist in the world (Koul, 2008).

As far as many other languages, auxiliaries in the Urdu language hold a significant position as far as grammar is concerned, however, in this paper, its syntactic and semantic nature is investigated. From earlier studies, it is observed that many scholars especially grammarians stated Hona as the only auxiliary that determines the tense (Naseer, 2010, Schmidt, 1999; Butt \& Ramchand, 2001; Manetta, 2019) and they opine that tenses are represented through multiple forms of Hona e.g., past, present and future. On the basis of their findings, Ehsan and Butt (2020) argued that Urdu auxiliary Hona only determines the tense-aspect in the sentence. Similarly, other researchers (Homer \& Bhatt, 2020; Ehsan \& Butt, 2020; Sharif, 2020; Ozarkar, 2020) suggest that light Vs that enjoy the status of auxiliaries in Urdu such as karna and Hona not only determine the tense but also determine the person and gender as well (Maqsood et al., 2019).

There are three basic types of verbs in Urdu as pointed out by Raza (2011) i.e. simple, complex, and even predicates. If we talk about the simple predicate, in Urdu, it consists of a mono-lexical entity, in which the root form of Vs remains the same, having a variety of stems such as direct and indirect causatives, transitive and intransitive (David et al., 2009). The illustrations of simple predicate from the work of (Raza, 2011) are listed below:

Table 1.

List of simple predicate (Raza, 2011)

\begin{tabular}{llll}
\hline Base Form & Intransitive Stem & Transitive Stem & Causative Stem \\
\hline Bag & Baj & Bajo & Bajva \\
Pit & Pit & Pit & Pitva \\
\hline
\end{tabular}

A complex predicate consists of two or more predicates resulting in one clausal arrangement. The first predicate takes a noun, verb, or adjective on which the meaning of the whole predicate depends, whereas, the meaning of the whole predicate contains a light verb which generally has tense, number, and gender inflection with it (Butt, 1995; Mohanan, 1994; Raza 2011). The general example of $\mathrm{V}-\mathrm{V}$ from the work of Raza (2011) is kat mar, ker guzar, char dhoor etc. Further, he claims that two verbs sometimes have similar semantic content when function collectively and they give rise to more abstract semantic content which may have 
altogether different meanings as compared to the individual verb (Raza, 2011). He regards them as even predicate.

In the case of tense inflection, Verbs can be classified into tensed and non-tensed Verbs (Collin \& Hollo, 2016). If we talk about English, the tensed verb forms are present and past tense. Consider the following illustrations in this respect:

2(a) The students arrive at 8am daily. [Present Tense]

\section{2(b) They enjoyed all night. [Past Tense]}

Events and states take place within a time period accounting for the time of utterance in the present tense, whereas, in the past tense, they occur before the time of speaking (Griffiths, 2006; Fleischhauer \& Neisani, 2020). The verbs in the above examples show the connection between time and action of utterance, thus, they are termed as tensed verbs. The present participle, past participle, and gerund forms of verbs in English are considered as non-tensed forms of verbs because their formation depends upon the addition of helping Vs to the root forms such as:

\section{3(a) Smoking is injurious to health. [Gerund]}

3(b) They are laughing very loudly. [Present Participle]

3(c) She was washing the clothes. [Past Participle]

All these verbs are not able to come up with an event within a time frame, as a result, they are considered as non-tensed verbs.

As regards Urdu, many researchers and linguists agree that kerna and Hona are the verbs that inflect for person, gender, number, and tense (Butt \& Ramchand, 2001; Maqsood et al., 2019). Butt and Ramchand (2001) in their work have explained the Urdu auxiliary Hona regarding tense formation. Butt (2003) reckons that auxiliaries are not the main and actual Vs rather they come up with main $\mathrm{Vs}$ to help in constructing a variety of other verb forms or they play the function of enhancing the meaning of the main Vs in a sentence (Humayoun et al, 2006). As Butt (2003) further explains that the most important and useful auxiliary verb in the Urdu language is Hona which assists the grammarians to form multiple verb forms such as past perfect, past indefinite, present, and many other future forms as well. Butt and Ramchand (2001) assert that there are certain auxiliary verbs that show the completion of an event such as Jana (G0), Laina (Take), Daina (give), Rehna (stay), etc.

Similarly, Börjars and Burridge (2019) have explained different scenarios in which these auxiliaries are used. Another particular auxiliary verb is Cukna which shows the accomplishment of an action. Many other types of auxiliaries are used to express ability, permissibility, and possibility i.e, Sakna, Dena, Pana, etc. Butt and Lahiri (2013) claim that auxiliaries such as Kerna, Jana, Rehna also reveal the habitualness of the subject. Abbas and Khan (2009) have also discussed auxiliaries regarding tense formation. They believe that present imperfect can be formed with the addition of auxiliaries of Hun. Likewise, past imperfect can be formed with the help of auxiliary Tha (was). As regards Schmidt's (1999) and Kulkarni's (2020) work, the auxiliary form Hona is such an auxiliary that could inflect with tense. He claims that present tenses (habitual and continuous) use the present tense auxiliary Hona, in contrast, past tenses use the auxiliary Tha.

Many researchers have used different terms for Urdu auxiliaries regarding the nature of the function that they perform in an utterance such as light verbs (Butt 1995; Diesing, 1997) intensifier (Schmidth,1999), modal auxiliary (Abbas \& Khan, 2009, Bhatt et al., 2011; Wade, 2020). However, all these Vs are explained and discussed under the umbrella term AUXILIARIES as such they do not enjoy the status of main verbs and are used to assist the main verbs in grammatical structure. According to the above facts and details, in previous studies, the tense auxiliary is mainly assigned to Ho. Verbs, irrespective of main Vs are explored and discussed with a great deal by researchers (Butt, \& Geuder, 2001; Butt, 2003; Butt \& Rizvi, 2010; Elenbaas, 2013; Harish \& Rangan, 2020; Khokhlova \& Zakharin, 2020; Sardaraz, 2020) and are treated in isolation and every scholar has termed them on the basis of the nature of their functions. Eventually, in the present research, Vs are undertaken to examine both grammatically and syntactically within the framework of X-bar theory. Furthermore, they are also examined semantically on the basis of meaning which they add to the main Vs in a well-formed grammatical sentence. Therefore, a comparative study of auxiliaries has been conducted in Urdu and English to unveil the differences found between the two languages, though, they are considered as mirror languages to each other (Hinrichs et al., 2020). The study would be significant as it is syntactical in nature and would add literature in 


\section{AMAZONDA}

the field of syntax. Further, it would be helpful for a better understanding of these two languages. The study addresses the following research questions:

1. What is the nature of Urdu and English auxiliaries?

2. What semantic content do they add to the meaning of main Vs in Urdu and English?

3. How are auxiliaries represented syntactically in Urdu and English?

4. How do Urdu and English behave differently or similarly in terms of auxiliary movement?

\section{Research Method and Materials}

The current study examines the grammatical and syntactical function of auxiliaries in Urdu and English to draw certain distinctions regarding the behavior, syntactic representation, and semantic content which auxiliaries add to the main Vs by employing the theoretical framework of X-bar theory within the field of the minimalist program. The X-bar theory is considered as a fundamental theory that represents the relationships between the constituents of a sentence in the computational system which are taken from the lexicon. It is regarded as a theory of P-Structure characteristics present in almost all natural languages across the world. It explains specifically three rules which are applicable to all the grammatical categories because these rules are considered as category neutral. The fundamental three rules of X-bar theory establish three major constituents in addition to the head, as a specifier, complement, and adjunct. The head in the sentence selects the complement as its sister, which is considered as bounded by the sub-categorization (obligation of the head).

Then, the specifier is selected as the daughter of the XP phrase and the sister of $\mathrm{X}$ in a syntactic representation. Since specifier pioneers the head, therefore, it is bound to be only one per phrase representation. If we move forward towards adjuncts, they can occur at any level in the X-bar presentation. They can occur more than once in a phrase structure, due to which, it is regarded as a recursive process (Newson et al, 2006; Shim, 2016; Slade, 2020; Suleybanova et al., 2019). The purpose of applying X-bar theory on Urdu and English auxiliary PS (phrase structure) is to unveil the sharp differences between Urdu and English in terms of the behavior of auxiliaries, semantic content which they add to main Vs, the syntactic representation of auxiliaries and how does their movement take place.
Hence, for the current study, data were collected from authentic sources (Urdu and English textbooks and grammars) which could provide a diverse range of possible usage of Urdu and English auxiliaries. From these sources, the researchers easily came up with a variety of VPs because all the content in these sources covered different aspects of life. Having published by well experienced and educated editorial boards, these sources were considered as reliable and authentic material for data collection and the editions of 2009 to 2012 were selected, from where 200 sentences were extracted to use in the current study. The collected data were analyzed grammatically in the terms of morphology, and syntax, through tree-representation and their movement. Furthermore, the data were analyzed semantically in order to check what sort of semantic content particularly they add to the overall meaning of the sentence and main Vs. In the end, a descriptive detail was provided to highlight the phenomenon of auxiliaries both in Urdu and English as well as what sort of differences do they possess.

\section{Data Analysis and Discussion}

As mentioned earlier, Urdu auxiliaries are mainly categorized into perfective, imperatives, infinitive, and habitual on the basis of the function which they perform. In Urdu, auxiliaries are categorized morphologically on the basis of the ending regular morphemes. The auxiliaries that end in aa/ai/ein are such a kind of auxiliaries that usually mark the perfect aspect of the tense. They represent the completion of a task and could inflect with a number, gender, and person, morphologically. Consider the following example in this respect.

1[a] Main kar aya Sub Verb Aux

To illustrate the reason why aya is labeled as auxiliary in the sentence $1[\mathrm{a}]$, consider another example $1[\mathrm{~b}]$

\section{1[b] Main aya \\ Sub Verb}

In both examples $1[\mathrm{a}, \mathrm{b}]$, we can see the word aya but in sentence [a], it is treated as auxiliary and in sentence $[b]$ it is enjoying the status of the main verb. The reason is that in the first sentence $\mathrm{Kar} / \mathrm{do}$ is treated as the main verb and here aya shows the completion of a task and treated as auxiliary because it is performing the function of aid in support of main V kar. Here, it is used to add certain semantic content to convey the 
meaning of a sentence. To elaborate it in detail, look at the following example:

\section{$1[\mathrm{c}] *$ Main kar Sub Verb}

This sentence is grammatically wrong in Urdu grammar because it is not conveying proper meaning. It represents incompleteness of a task because the listener is unable to comprehend what in fact the speaker wants to convey. From the above examples $1[a, b, c]$, it becomes evident why aya is treated as an auxiliary in sentence 1 [a] and why sentence $1[\mathrm{c}]$ is ungrammatical without the addition of the word aya as auxiliary because it performs the function to support the meaning of main verb kar, so that the reader can get rightly what the speaker wants to convey.

In the Urdu language, there are four levels of conveying respect such as aa/ao/aien/ayie. Nevertheless, in respect of perfective, auxiliaries represent only one respect level because of their incompatibility with other respect levels. If we add them to another respect level, they might lose their morphological form of aa/ai/ain. Furthermore, perfective auxiliaries can also mark gender and covey proper information about numbers as well. Consider table four in this respect.

Table 2.

Urdu Perfective Auxillaries.

\begin{tabular}{lllllll}
\hline EX & MF & N & G & P & ASP & RL \\
\hline Mein samjh paya & aa & singular & masculine & first person & Perfective & level 1 \\
Tu samjh paya & aa & singular & masculine & second person & perfective & level 1 \\
Wo samjh paya & aa & singular & masculine & third person & Perfective & level 1 \\
Mein samjh pai & ai & singular & feminine & first person & Perfective & level 1 \\
Tu samjh pai & ai & singular & feminine & second person & Perfective & level 1 \\
Wo samjh paien & aien & Plural & neutral & third person & Perfective & level 1 \\
Hum samjh paye & aye & Plural & neutral & first person & perfective & level 1 \\
\hline
\end{tabular}

Note: Ex stands for example, MF stands for morphological form, N stands for number, G stands for Gender, $\mathrm{P}$ stands for person, Asp stands for aspect, RL stands for respect level in Urdu language

The Urdu auxiliaries which end with 'taay' also show the repetition of actions. These also elucidate that the actions are not completed yet.
Aalif/yee, yein come at the end of taay which exhibit the conjugation of number, gender and person.

Table 3.

Habitual Auxiliaries Conjugations.

\begin{tabular}{lllllll}
\hline Ex & $\mathrm{F}$ & $\mathrm{G}$ & $\mathrm{N}$ & Person & Asp & RL \\
\hline Main samjh pata & Taa & masculine & Singular & $1^{\text {st }}$ & Habitual & L 1 \\
Tu samjh pata & Taa & masculine & Singular & $2^{\text {nd }}$ & Habitual & L 1 \\
Wo samjh pata & Taa & masculine & Singular & $3^{\text {rd }}$ & Habitual & L 1 \\
Main samjh pati & $\mathrm{Ti}$ & feminine & Singular & $1^{\text {st }}$ & Habitual & L 1 \\
Tu samjh pati & $\mathrm{Ti}$ & feminine & Singular & $2^{\text {nd }}$ & Habitual & L 1 \\
Wo samjh pati & $\mathrm{Ti}$ & feminine & Singular & $3^{\text {rd }}$ & Habitual & L 1 \\
Hum samjh paaty & Taay & masculine & Plural & $1^{\text {st }}$ & Habitual & L 1 \\
Tum samjh paty & Taay & masculine & Plural & $2^{\text {nd }}$ & Habitual & L 1 \\
Wo samjh paty & Taay & masculine & Plural & $3^{\text {rd }}$ & Habitual & L 1 \\
Hum samjh patein & Tein & feminine & Plural & $1^{\text {st }}$ & Habitual & L 1 \\
Tum samjh patein & Tein & feminine & Plural & $2^{\text {nd }}$ & Habitual & L 1 \\
Wo samjh patein & Tein & feminine & Plural & $3^{\text {rd }}$ & Habitual & L 1 \\
\hline
\end{tabular}

Note: Ex stands for example, MF stands for morphological form, N stands for number, G stands for Gender, P stands for person, Asp stands for aspect, RL stands for respect level in Urdu language 


\section{AMAZONDA \\ 1vvestig.}

In the following examples it can be seen how habitual can perform the role of auxiliaries. According to the example, (a) samajhta is working as a main verb. And in (b) the word aata is acting as an auxiliary and smajh is as a main verb.

Example (a)

Wo rooz smajhta hai

Subj, adv, verb, tense aux

Example (b)

Wo rooz smajh paata hai

Subj, adv, main verb, aux, tense aux

It is noticeable from the table that level 1 of respect is indicated by habitual auxiliaries and morphological constraints do not concede other levels; as habitual morphology is lost by ensuing the morphology of other levels e.g tum samjh aao, aap samjh ayein, aap samjh aayee.

Tense auxiliaries are of great importance. The above-mentioned table shows that without tense auxiliaries, the habitual auxiliaries are considered incomplete. Proper meaning to habitual auxiliary and complete sense is provided by adding tense auxiliaries. Look at the following examples:

Example (a,b,c,d)

a) Wo rooz nahata.

b) Wo rooz naha kar aata tha.

c) Wo rooz naha kar aata hai.

d) Main rooz naha kar aata hon.

The meaning to habitual actions is given by all past and present tense auxiliaries after avoiding $2^{\text {nd }}$ and $3^{\text {rd }}$ person auxiliaries of subjunctive.

Presumptive auxiliaries are formed when future auxiliaries are combined with habitual auxiliary.

Example

Wo rooz naha kar aata ho ga.

Many grammarians have discussed the infinitive forms and their functions like other auxiliaries. According to Bhatt and Dayal (2020), infinitives behave like verbal nouns and shows actions, and always have naa at the end due to which they (infinitives) in the light of the objectives of the current study act like auxiliaries.

Table 4.

Inflection of Infinitive Auxiliaries.

\begin{tabular}{lllllll}
\hline Example & form & gender & person & number & aspect & RL \\
\hline Main ny cake bnana $\mathrm{h}$ & $\mathrm{na}$ & Masculine & $1^{\text {st }}$ & Singular & Infinitive & Level 1 \\
Tum ny cake bnana $\mathrm{h}$ & $\mathrm{Na}$ & Masculine & $2^{\text {nd }}$ & Singular & Infinitive & Level 1 \\
Us ny cake banana $\mathrm{h}$ & $\mathrm{Na}$ & masculine & $3^{\text {rd }}$ & Singular & Infinitive & Level 1 \\
Mai by roti bnani $\mathrm{h}$ & $\mathrm{Ni}$ & Feminine & $1^{\text {st }}$ & Singular & Infinitive & Level 1 \\
Tim ny roti bnani $\mathrm{h}$ & $\mathrm{Ni}$ & Feminine & $2^{\text {nd }}$ & singular & Infinitive & Level 1 \\
Us ny roti bnani h & $\mathrm{Ni}$ & Feminine & $3^{\text {rd }}$ & singular & Infinitive & Level 1 \\
Mai ny cake bnanay hn & $\mathrm{Nay}$ & Masculine & $1^{\text {st }}$ & plural & Infinitive & Level 1 \\
Tum ny cake bnanay hn & $\mathrm{Nay}$ & Masculine & $2^{\text {nd }}$ & plural & Infinitive & Level 1 \\
Us ny cake bnanay hn & nay & masculine & $3^{\text {rd }}$ & plural & Infinitive & Level 1 \\
Mai ny rotiya bnani hn & ni & Feminine & $1^{\text {st }}$ & plural & Infinitive & Level 1 \\
Tum ny rotiya bnani hn & ni & Feminine & $2^{\text {nd }}$ & plural & Infinitive & Level 1 \\
Us ny rotiya bnani hn & ni & feminine & $3^{\text {rd }}$ & plural & infinitive & Level 1 \\
\hline
\end{tabular}

Examples

(a) mainy pass hona hai.

Sub, noun,inf, tense aux

(b) mainy pass ho jana hai

Sub, noun, verb, aux, tense aux

In example (a) hona is infinitive which is functioning as a main verb but in example (b) it is acting as an auxiliary.
After Morphological analysis, the obtained data are analyzed syntactically to check all the possible combinations in which auxiliaries could be used with main verbs by offering their syntactic representation through tree diagrams. In earlier works (Bhatt \& Dayal 2020; Naseer, 2010; Schmidt.1999), the focal point of discussion was based on compound Vs and the arrangement of compound Vs in a grammatical structure. Complex predicates along with their syntactic representation were discussed later by 
(Butt,1995, Butt \& Gillian, 2003, Butt \& Holloway, 2009; Das, 2006, Ahmed, 2010, Raza, 2011). Homer and Bhatt (2020) particularly deal with the topicalization of Vs along with their duplication. In all the prior studies (Ehsan \& Butt, 2020; Homer \& Bhatt, 2020) related to this field, primary importance was mainly attributed to Urdu Compound Vs and their variations in syntactic representation. The present study is different from previous studies in the sense that it is aimed to explore the auxiliaries in Urdu and English. From literature, it is noticed that in VP, the main verb is always preceded by auxiliaries.

Moving from a simple grammatical structure to a complex structure, the place of Vs remains same. If we talk about the tense auxiliaries in the Urdu language, they will always occupy their syntactic position at the end of a sentence. As discussed earlier, there are four basic types of Urdu auxiliaries, from which only "perfective" are such kind of auxiliaries which have the ability to the tense auxiliaries retaining the grammatically of the sentence within MP (Minimalist program). All other types of auxiliaries do not have the ability to elite their tense auxiliaries because if they drop their tense auxiliaries then they violate the norms of grammaticality of MP which suggests that the human computational system can generate only and only grammatical structures. For example:

Wo chilaya

$\mathrm{Sb}+$ verb+aux

Wo chila chukka

Sub+verb+aux

Wo chila liya

Sub+verb+aux

The examples cited above illustrate that the perfect auxiliary aa shows the completion of a sentence without having any other tense auxiliary because the perfect auxiliary itself is explaining the tense-aspect that is perfect. While the other types of auxiliaries such as progressive and habitual would result in the ungrammaticality of sentence if they drop their tense auxiliaries. Furthermore, the sentence would not convey the meaning of completeness either the said task is completed or not. Consider the following examples in this respect:
a) Wo chilata a rha hai
b) *Wo chilata aa rha
c) Wo chilata chala a raha hai
d) Wo chilata challa a raha
e) Wo chilata chalaaaraha hota hai
f) Wo chilatan chala aaa raha hota

It is clear from the above examples that when all the sentences have tense auxiliary "hai" they are well-formed grammatical sentences conveying the completion of a task within a particular time. However, as the tense auxiliary "hai" is removed from them, first, they miss the grammaticality of the sentence, and secondly, it shows the incompleteness of an action. In the case of the English language, the tense auxiliaries have overt and covert positions in the syntactic arrangement of a sentence. For example:
(i) I do
(ii) I did
(iii) $I \mathrm{com}$

In all the above sentence, the main verbs $d o$, did, and come have present and past tense auxiliaries existing covertly with them which is inseparable from the main verb. All the sentences are said to be well formed and grammatical similar to the Urdu example (10, a, b and c). Similar to the Urdu language, in English language, progressive and habitual auxiliary because doing this, the formed structures are said to be ungrammatical such as,
a) Sean was reading book
b) *Sean reading his book
c) She used to talk more often
d) *She talk more often
e) She may keep going on and on
f) *She may used to go on and on

When the auxiliary in the above sentence "is" and "would" be dropped from the sentence they lost their grammaticality and furthermore, they lost their semantic content of completion of a task. Despite the similarity, the major difference is found between English and Urdu with respect to the placement of an auxiliary. In Urdu language, tense auxiliary always occupies its synthetic position at the end of the sentence, which can be observed from the data quoted above, whereas, in English, the tense auxiliary has its position before the main verb in a sentence.

Urdu auxiliaries have multiple combinations with the main Vs in a grammatical sentence and with each other's as well. These combinations are explained with the help of syntactic representation in the form of tree diagrams. This might help to unveil the true nature of auxiliaries in the sense, how different auxiliaries and their syntactic combinations with main Vs could occupy similar slots in the respective tree diagrams. For example: 
[1] Wo rotaa hai

Its syntactic tree within the framework of X-bar theory can be constructed as:

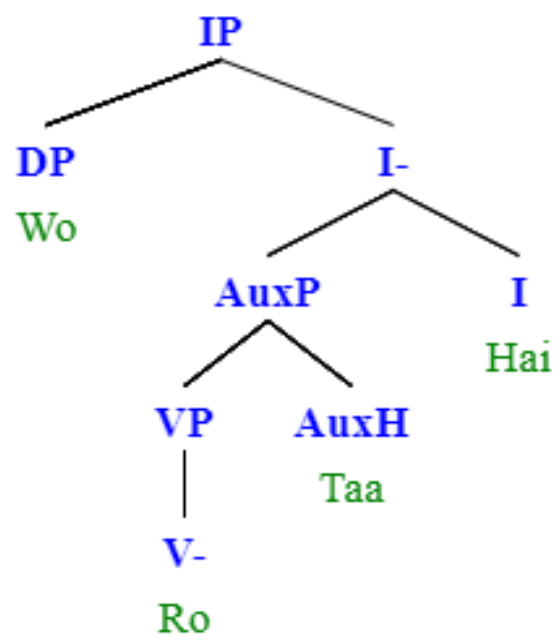

Diagram1. Syntactic representation of habitual inflectional auxiliary.

In this diagram, the main verb "RO" form the v' having habitual inflection "TA" as its sister node to form AUX' phrase because the habitual inflection "TA" with the main verb is a part of the auxiliary phrase, which further attracts the tense auxiliary "HAI" to form I' which combine with the determiner "WO" to form IP. Since the main verb always occupies the same position in a syntactic tree under the node $\mathrm{V}$ and the inflection goes under the AUX phrase having tense auxiliary as its sister. Consider the following illustrations in this respect having one or more than one auxiliaries in the sentence.

[2] Wo rotaa rehta hai.

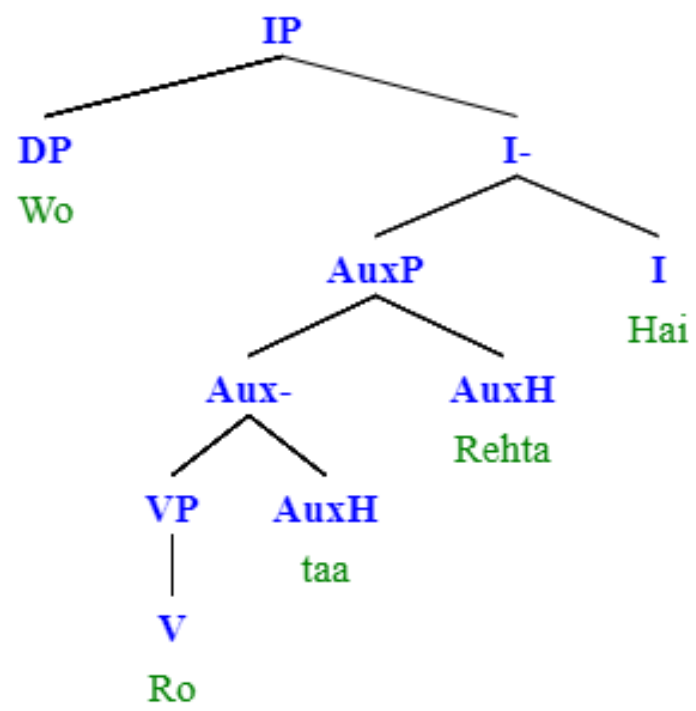

Diagram2. Syntactic representation of habitual auxiliary.

This diagram conveys the information about auxiliary "Rehta" and inflectional auxiliary "Taa" attached with the main verb "RO". The syntactic representation for the above sentence shows that VP which is the head of Verb as the habitual auxiliary and verb phrase are said to be sisters of each other because they both rest on a similar plane. The habitual auxiliary in the above sentence can be replaced with the other forms of auxiliaries (progressive and perfective) resulting in the same syntactic structures with respect to a tree diagram, such as:

[2a] Wo rotaa raha hai 


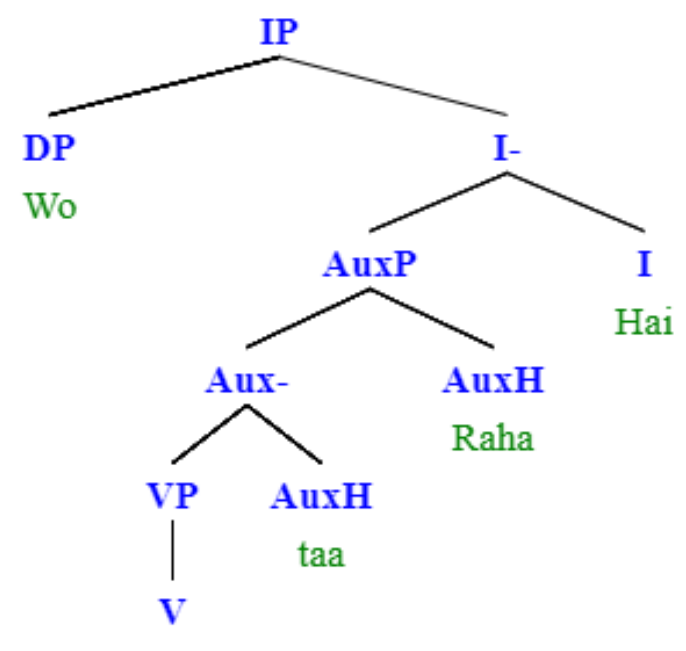

Ro

Diagram2(a). Syntactic representation of progressive auxiliary.

The above diagram is a syntactic variation of the diagram (2a) with the significant difference of replacing the habitual auxiliary "REHTA" in example (2) with the progressive auxiliary "RAHA" in a sentence (2a). In the above diagram, progressive auxiliary "RAHA" is the head of the auxiliary phrase.

[2b] Wo roo chukka hai

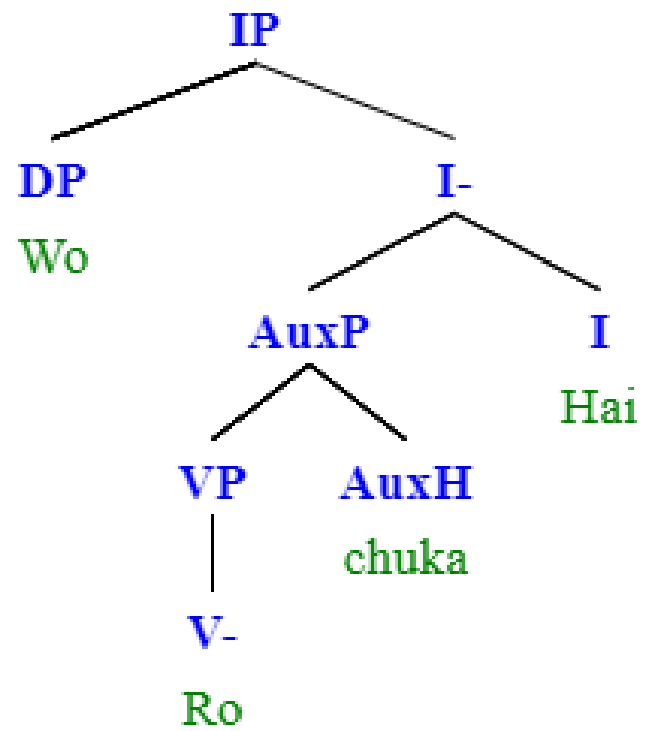

Diagram2(b). Syntactic representation of perfective auxiliary.

This diagram illustrates that AUX phrase can have perfective auxiliary as its head to create semantic difference but does not mark any syntactic difference because the replacement of progressive auxiliary "RAHA" in (2a) with the perfective auxiliary "Chuka" in (2b) does not mark any significant difference in the construction of the syntactic tree. If we replace the progressive, habitual, and perfective auxiliaries with model auxiliaries, no difference could be observed in their tree diagram construction. Consider the following trees in this respect:

[2c] Wo roo sakta hai 


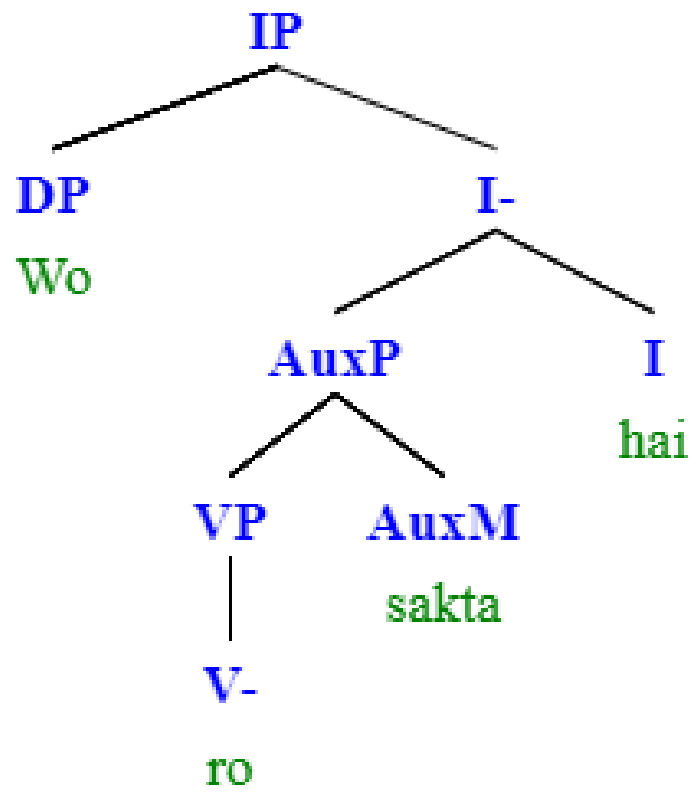

Diagram2(c). Syntactic representation of modal auxiliary.

[2d] ussay rona chayie tha

Its syntactic tree is constructed below:

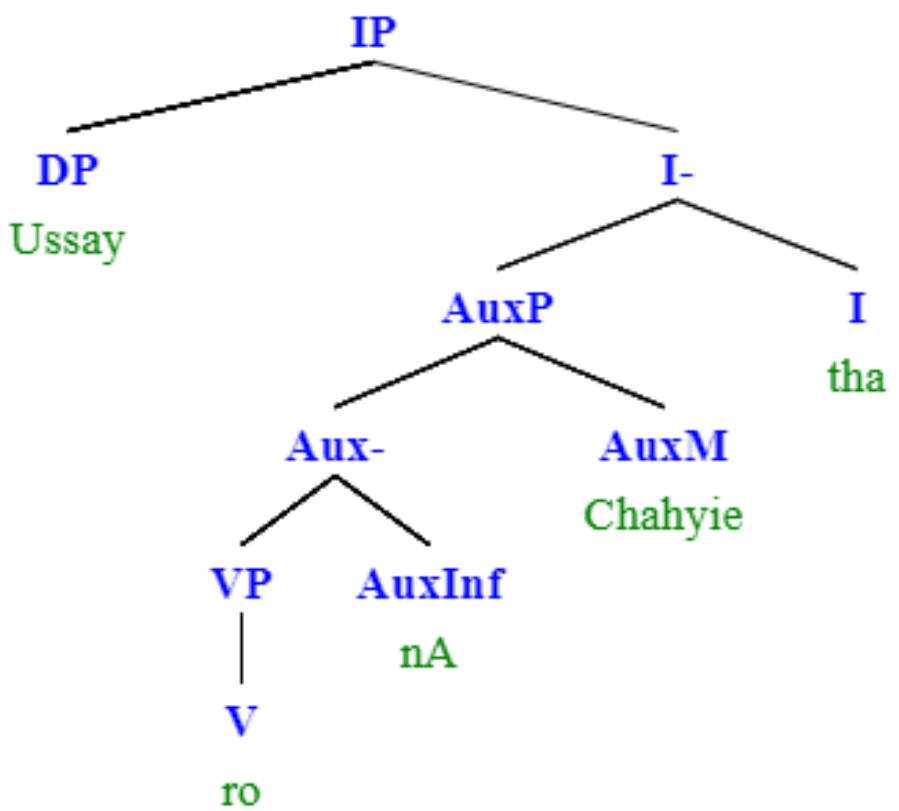

Diagram2(d). Syntactic representation of modal and tense inflectional auxiliary.

These diagrams show that AUX phrase of the syntactic tree (2) can also replace the auxiliary with AuxMod "CHAHYIE", also having the tense auxiliary. It has the ability to elite the tesne auxiliary according to the said requirements. Consider another example in this respect.

[2e] Wo roo para hai 


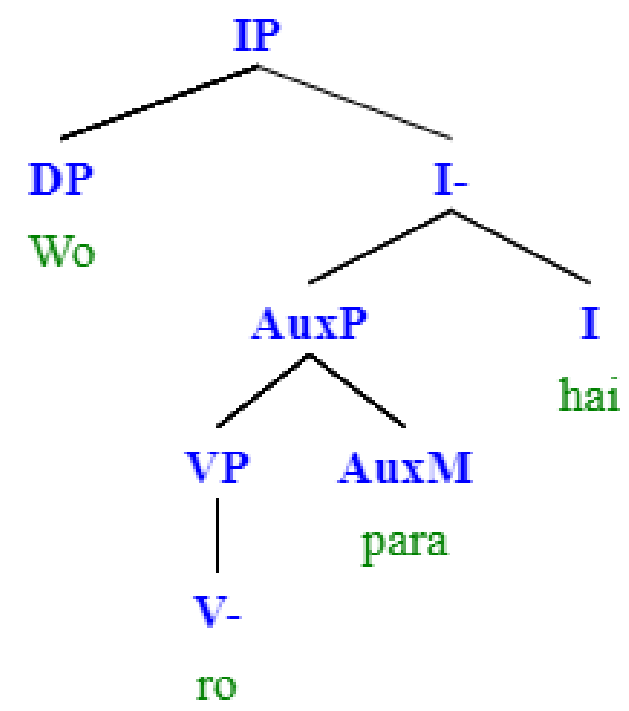

Diagram2(e). Syntactic representation of modal auxiliary.

In both diagrams (2d) and (2e), the sentences have the ability to drop the tense auxiliary because without it, they are capable of conveying proper information and retain the status of grammaticality. For example:

(2e) Wo roo para (2d) Ussay rona para.
In the above examples, we can see that in Urdu sentences, a main verb can have one auxiliary and more than one (progressive, habitual, perfective and model auxiliaries) which can occupy their positions in the AUX phrase as a single syntactic entity. In addition, VP can have habitual auxiliary along with the intensifier as illustrated below:

[3] Wo rotaa chala jata hai

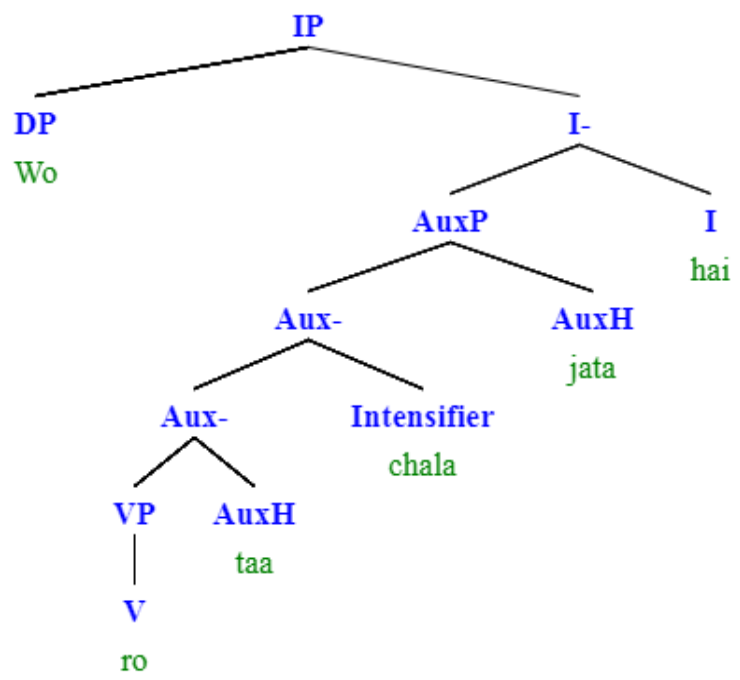

Diagram3. Syntactic representation of intensifier and habitual auxiliary.

The above diagram illustrates the fact that AUX phrase can be the head of multiple syntactic entities. First, it can take the verb inflection "TAA" attached with the main verb. Secondly, it can take intensifier "CHALA" and habitual auxiliary "JATAA" respectively. AUXP is the head of the intensifier "CHALA" and "JATA" which is habitual auxiliary. The only difference is that the position of intensifier in the syntactic tree is fixed and the habitual auxiliary could be replaced with other auxiliary, as:

[4] Wo rotaa ja raha hai 


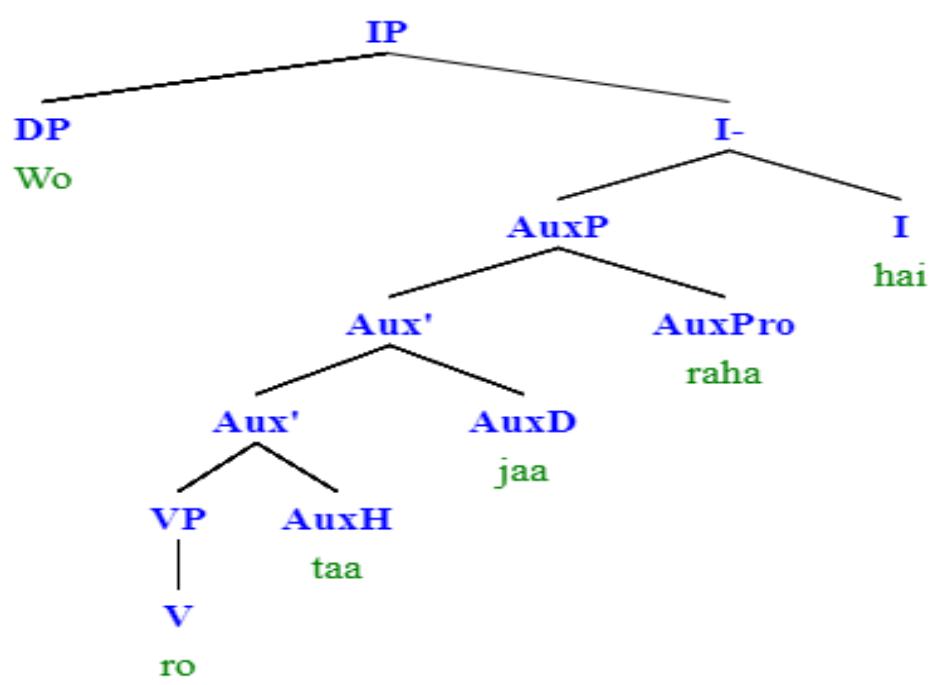

Diagram4. Syntactic representation of progressive and durative habitual auxiliary.

This diagram further illustrates the different combinations of Urdu auxiliaries with the main verb. Here in this diagram, the auxiliary phrase is serving as head of progressive and durative auxiliary "RAHA" and "JATA" respectively. It can further add intensifier to it such as:

[5] Wo rotaa chala jaa raha hai

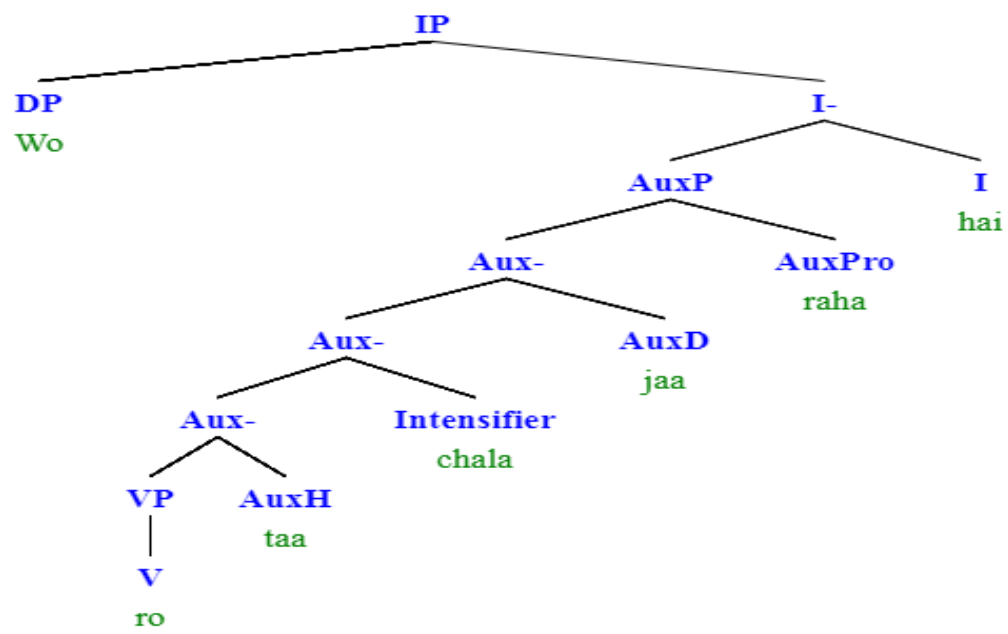

Diagram5. Syntactic representation of intensifier, progressive and durative habitual auxiliary.

The above mentioned diagrams show that an auxiliary phrase can be the head of any habitual auxiliary, progressive, perfective and modal auxiliaries (examples 2, 2a, 2b, 2c, 2d and 2e). All these illustrations validate that the replacement of auxiliaries with other types do not mark any difference in the construction of syntactic trees. As Aux phrase can have habitual auxiliary and intensifier (example no.3). It can also head the progressive auxiliary, durative auxiliary along with the intensifier (example $4 \&$ 5). Similarly, English main verb could also have all these combinations with auxiliaries. To understand it, consider the following examples of different English main Verbs with different auxiliaries in this respect:

[6] He weeps.

Its syntactic tree representation is given below: 


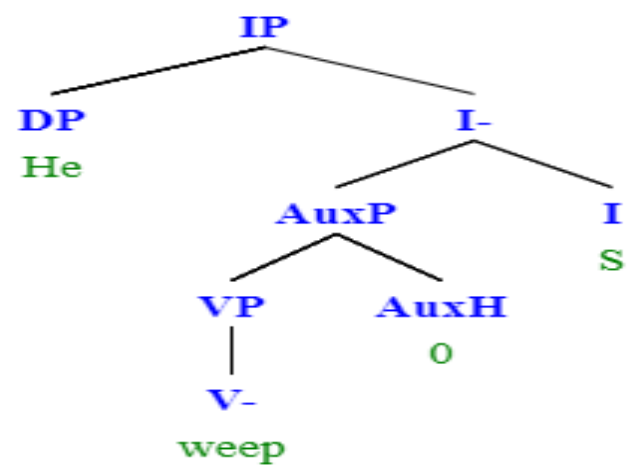

Diagram6. Syntactic representation of tense inflectional auxiliary.

In the above diagram, the auxiliary is in covert and is embedded within the main verb weep having present tense inflectional auxiliary in the form of "s". This shows that this sentence belongs to present indefinite tense. The above sentence can be replaced with other types of auxiliaries similar to the Urdu examples discussed above. Such as:

[6a] He is weeping.

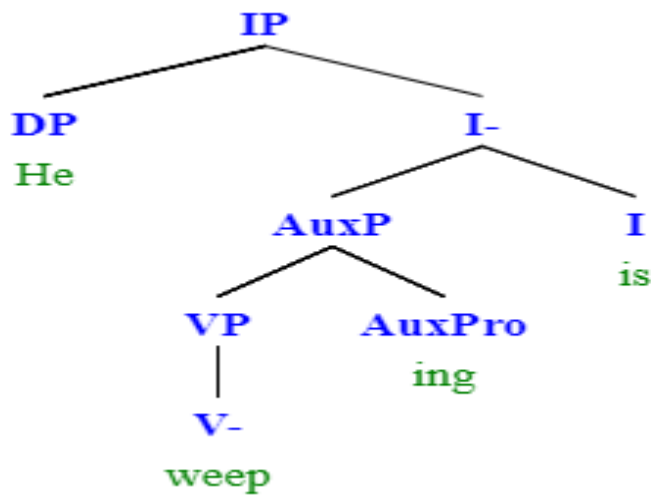

Diagram6(a). Syntactic representation of Progressive auxiliary.

The current tree diagram is the replica of diagram (6), the difference is that in (6a) a progressive auxiliary is added to the main form of verb as weep to weeping having "is" present tense auxiliary. The difference is that in Urdu examples progressive auxiliary is not embedded within the main verb as it is embedded within the main verb in English language.

Similarly, English main Vs could also have habitual auxiliaries with them in a grammatical structure like:

[6b] He keeps on weeping

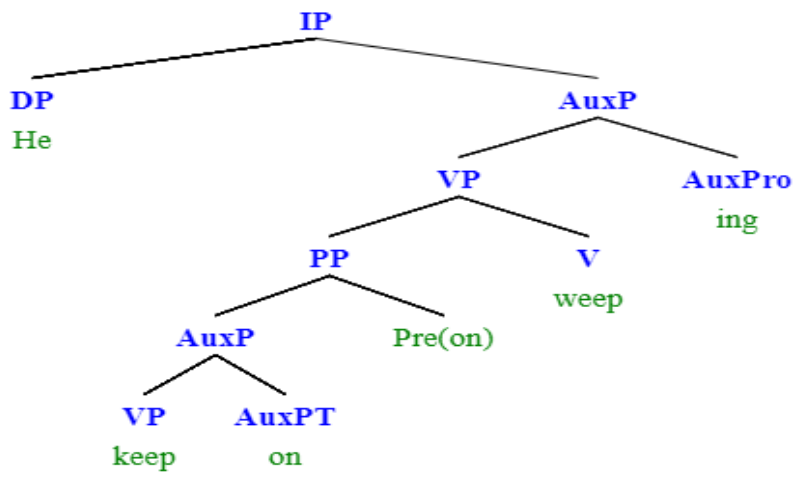

Diagram6(b). Syntactic representation of habitual auxiliary. 
The habitual auxiliaries could be replaced with perfective auxiliaries as well.

[6c] He has wept.

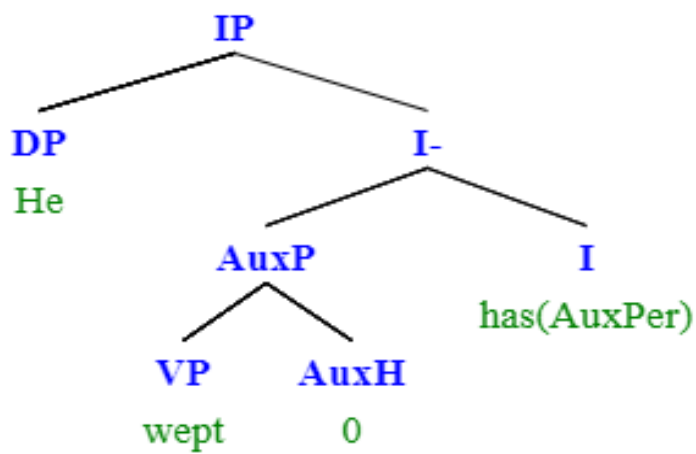

Diagram6(c). Syntactic Representation of habitual auxiliary.

In the above tree diagram, perfective auxiliary is used in the place of habitual auxiliary. In addition to this, modal auxiliary can also be used with the main Vs in English.

[6d] He should weep.

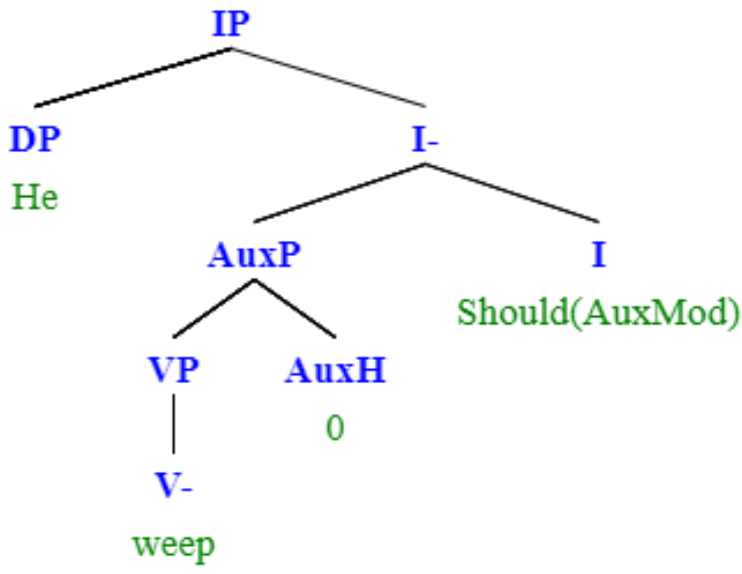

Diagram6(d). Syntactic representation of modal auxiliaries.

Furthermore, auxiliaries can undergo syntactic movement in English as compared to Urdu

[7] Is he weeping? language.

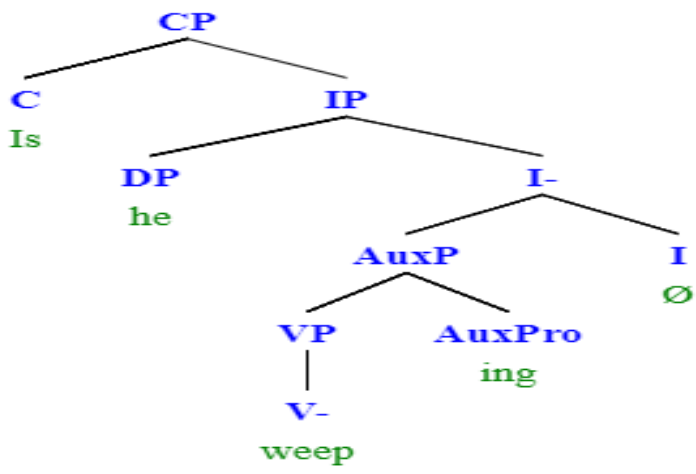

Diagram7. Syntactic Movement of Tense Auxiliary. 
In this tree diagram, the auxiliary "is" is moved from its latent position of "I" towards the specifier position "CP" in order to form complementizer phrase which grammatically shows the syntactic representation of interrogative sentence. When such movement takes place, its leaves behind a null auxiliary as shown in the above diagram (7).

As discussed, so far, auxiliaries are said to be used with main $\mathrm{Vs}$ in order to add a specific semantic content because they change the semantic dimensions of main Vs. They alone do not possess any significant meaning to convey. As discussed above, during morphological analysis of auxiliaries that they are used to convey four different meanings of action completion, the habitual nature of an action, infinitive behavior and imperative as well. All these auxiliaries are discussed individually above but they could have semantic contributions when used in different auxiliaries' combinations to show how they contribute in a phrase and sentence level semantically. Consider the following examples in this respect:

[A] Wo nachtay hain

[B] Wo nachtay rehtay hain

[C] Wo nachtay jaty hain

[D] Wo nachtay chaly jaty hain

[E] Wo nachtay hotay hain

[F] Wo nachtay phirtay hain

[G] Wo nachtay chaly jaty hain

$[\mathrm{H}]$ Wo nachtay hi jaty hain

[I] Wo naach rahy hain

[J] Wo nachtay ja rahy hain

[K] Wo nachty chaly ja rahy hain

[L] Wo nachtay hi chaly ja rahy hain

[M] Wo nachtay ja rahy hotay hain

In all the above sentences, there may be one auxiliary and might be possible that there are more than one auxiliaries. In example A, there is only one auxiliary which marks the perfect aspect ending in "TAY". In B, there is an aspectual auxiliary that marks the meaning of continuity and repetition of an action. For instance, the auxiliary "REHTAY" in example B shows the continuity of action of dancing. In example $\mathrm{C}$, the main verb of the sentence "NACHTAY" and "JATAY" as auxiliary reveal the semantic content of habitualness and repetition of an action but here the auxiliary "JATAY" further presents another semantic content which is related to direction and duration as well. In sentence d, the auxiliary "CHALAY" is added which conveys the meaning of duration of an action (nachtay) for a longer period of time as compared to sentence C. Furthermore, the examples I to $\mathrm{L}$ demonstrate the existence of multiple auxiliaries having progressive aspect "RAHA" which illustrates that how the addition of multiple auxiliaries enhance the meaning of a sentence with respect to repetition, duration, direction and continuation as well.

\section{Conclusion}

It can be noticed that auxiliaries on the basis of their behavior can be classified into two main categories i.e. tense and aspectual auxiliaries, which are further divided into sub-categories. Tense auxiliary are further sub-divided into present tense auxiliary, past tense auxiliary and future tense auxiliary, while aspectual auxiliaries can be further divided into inflectional and noninflectional auxiliaries. Inflectional auxiliaries allow the main Vs to inflect with the inflectional morphemes such as "ye, wao, non, tay" as the main verb "kar" could have inflectional morphemes to form different morphological forms such as "karna", "karo", "Kartaa", "Kartay" etc. In contrast to inflectional auxiliaries, there are also other auxiliaries that do not allow the main verb to have such inflectional morphemes with the base form. For example, "Wala" cannot have the inflectional morpheme because its addition results in ungrammaticality of sentence, which is not possible within the framework of universal grammar. It could have another fixation with it, due to which, it fixes the infinitive and gets inflected with number and gender. Further, certain variances are traced between Urdu and English auxiliaries. The sharp difference is related to the syntactic position of auxiliaries in both languages. In Urdu, auxiliaries always occupy their position after the main verbs in a sentence and their position is fixed. Apart from this, another significant difference which is observed in Urdu and English auxiliaries is that Urdu auxiliaries have the ability to mark number (singular \& plural) and gender (masculine \&feminine), however, English auxiliaries can only mark number. Another sharp difference, which is observed between the functionality of auxiliaries in both languages is related to the phenomenon of question formation. In Urdu, unlike English, auxiliaries cannot be moved from its latent position towards the specifier position at the beginning of the sentence in order to form question structures because if it happens then the sentence is considered as ungrammatical which may result in the violation of MP. In short, it can be said that both languages (Urdu \& English) have similarities and some specific differences as far as the syntactic movement and behavior of auxiliaries are concerned. Herein, the differences are explored and discussed however, future 


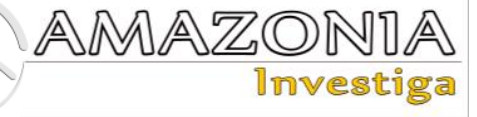

studies could be conducted in order to investigate why these differences occur and what is the tangible reason behind this. The findings of the study would prove helpful for understanding the semantic, grammatical and syntactical nature and behavior of auxiliaries comparatively in Urdu and English.

\section{References}

Abbas, Q., \& Khan, A. N. (2009, October). Lexical functional grammar for Urdu modal verbs. In 2009 International Conference on Emerging Technologies (pp. 7-12). IEEE. Ahmed, T. (2010). The unaccusativity/unergativity distinction in Urdu. Journal of South Asian Linguistics, 3(1). Alagbe, A. A. (2009). The English Primary Auxiliary Verbs: A Linguistic Theoretical Exercise. African Research Review, 3(2).

Bhatt, R., \& Dayal, V. (2020). Polar question particles: Hindi-Urdu kya. Natural Language \& Linguistic Theory, 1-30.

Bhatt, R., Bogel, T., Butt, M., Hautli, A., \& Sulger, S. (2011). Urdu/Hindi Modals. CSLI Publications

Börjars, K., \& Burridge, K. (2019). Introducing english grammar. Routledge.

Butt, M. (1995). The Structure of Complex Predicates. Stanford, CA: CSLI Publications

Butt, M. (2003). Light verbs in Urdu and grammaticalization Miriam Butt and Wilhelm Geuder. Words in time: Diachronic semantics from different points of view, 143, 295.

Butt, M., \& Rizvi, J. (2010). Tense and aspect in Urdu. Layers of aspect, 43-66.

Butt, M. (2010). The light verb jungle: Still hacking away. Complex predicates: Crosslinguistic perspectives on event structure. Cambridge University Press.

Butt, M., \& Geuder, W. (2001). On the (semi) lexical status of light verbs. Semilexical Categories: On the content of function words and the function of content words, 323-370.

Butt, M., \& Gillian, R. (2003). Complex Aspectual Structure in Hindi/Urdu. Oxford University Press

Butt, M., \& Holloway, T. (2009). On the Difference between Auxiliaries, Serial Verbs and Light Verbs. CSLI Publications.

Butt, M., \& Lahiri, A. (2013). Diachronic pertinacity of light verbs. Lingua, 135, 7-29.

Butt, M., \& Ramchand, G. (2001). Complex aspectual structure in Hindi/Urdu. M. Liakata, $B$. Jensen, \& D. Maillat, Eds, 1-30.

Collins, P., \& Hollo, C. (2016). English grammar: An introduction. Macmillan International Higher Education.
Das, P. K. (2006). Grammatical Agreement in Hindi-Urdu and its Major Varieties.

David, A., Maxwell, M., Browne, E., \& Lynn, N. (2009). Urdu Morphology. Maryland: Centre for Advanced Study of Language, University of Maryland.

Diesing, M. (1997). Light verbs and the syntax of aspect in Yiddish. Journal of Comparative Germanic Linguistics, 1(2), 119-156.

Ehsan, T., \& Butt, M. (2020, May). Dependency Parsing for Urdu: Resources, Conversions and Learning. In Proceedings of The 12th Language Resources and Evaluation Conference (pp. 5202-5207).

Elenbaas, M. (2013). The synchronic and diachronic status of English light verbs. Linguistic Variation, 13(1), 48-80.

Fleischhauer, J., \& Neisani, M. (2020). Adverbial and attributive modification of Persian separable light verb constructions. Journal of Linguistics, 56(1), 45-85.

Griffiths, P. (2006). Introduction to English semantics and pragmatics. Edinburgh university press.

Harish, B. S., \& Rangan, R. K. (2020). A comprehensive survey on Indian regional language processing. SN Applied Sciences, 2(7), 1-16.

Hinrichs, E., Kathol, A., \& Nakazawa, T. (Eds.). (2020). Complex predicates in nonderivational syntax. BRILL.

Homer, V., \& Bhatt, R. (2020). Restructuring and the scope of negation in Hindi- Urdu. Glossa: $a$ journal of general linguistics, 5(1).

Humayoun, M., Hammarström, H., \& Ranta, A. (2006). Urdu morphology, orthography and lexicon extraction. Chalmers tekniska högskola. Khokhlova, L., \& Zakharin, B. (2020, August). Hindi-Urdu light verbs revisited. In Book of Abstracts (p. 94).

Koul, O. N. (2008). Modern Hindi Grammar. Dunwoody Press 2008.

Kulkarni, A. (2020, August). Borrowing and disappearance of light verbs. In Book of Abstracts (p. 447).

Manetta, E. (2019). Verb-phrase ellipsis and complex predicates in Hindi-Urdu. Natural Language \& Linguistic Theory, 37(3), 915-953. Maqsood, B., Saleem, T., Aziz, A., \& Azam, S. (2019). Grammatical constraints on the borrowing of nouns and verbs in urdu and english. SAGE Open, 9(2), 2158244019853469.

Mohanan, T. (1994). Argument structure in Hindi. Center for the Study of Language (CSLI). Naseer, A. (2010). Tense and Aspect in the Context of Urdu. International Journal of Electrical \& Computer Sciences, IJECS-IJENS Vol: 10 No: 05. 
Newson, M., Hordós, M., Pap, D., Szécsényi, K., Tóth, G., Vincze, V. (2006). Basic English syntax with exercises. Budapest: Bölcsész Konzorcium Ozarkar, R. (2020). A special case of long distance agreement in Marathi. Glossa: A Journal of General Linguistics,5(1), 93. DOI: http://doi.org/10.5334/gjgl.698

Raza, G. (2011). Sub-categorization Acquisition and classes of Predication in Urdu. Konstanzer Online Publications System (KOPS).

Sardaraz, K. (2020). Syntactical Structure of English and Pashto Prepositions: A Case of INON Vs PUH-KE and PUH-BANDE. sjesr, 3(1), 76-88.

Schmidt, R. L. (1999). Urdu: An Essential Grammar. London: Routledge

Sharif, A. N. (2020). Causative alternation licensing in Urdu: An event structure account (Doctoral dissertation, University of Otago).

Shim, J. Y. (2016). Mixed verbs in codeswitching: The syntax of light verbs. Languages, 1(1), 8.
Slade, B. (2020). Verb Concatenation in Asian Linguistics. In Oxford Research Encyclopedia of Linguistics.

Suleybanova, M. U., Kieva, Z. H., Sultygova, M. M., Gasanova, U. U., \& Bidanok, M. M. (2019). Hypotaxis in inflectional and agglutinative languages. Amazonia Investiga, 8(22), 414-421. https://amazoniainvestiga.info/index.php/amazo nia/article/view/749/708

Wade, T. (2020). A comprehensive Russian grammar. John Wiley \& Sons.

Yusupov, A. F., Galiullina, G. R., Yusupova, N. M., \& Kajumova, Z. M. (2018). Grammatical development and functioning of the arab verbal forms in the old Tatar language of the 19th century. Amazonia Investiga, 7(13), 117-122. https://amazoniainvestiga.info/index.php/amazo nia/article/view/501/472 